\title{
Development of an Independent Type of Hybrid Power Generation System
}

\author{
Toshiro Hirose $^{1,2}$, Hirofumi Matsuo ${ }^{1}$, Yoichi Ishizuka ${ }^{1}$ \\ ${ }^{1}$ Nagasaki University, Nagasaki, 852-8521, Japan \\ ${ }^{2}$ Nishimu Electronics Industries Co., Ltd, Saga, 842-0032, Japan \\ E-mail: hirose@nishimu.co.jp
}

\begin{abstract}
In this paper, the optimum control technology of an independent type of hybrid power system with wind and solar power generation, which enables a stable power supply to the loads, proposed and developed. This system comprises wind power generation inverter, solar power generation inverter, bidirectional inverter for storage batteries, and engine generator. Each inverter is connected with engine generator in parallel, and is operated under redundant mode.
\end{abstract}

\section{INTRODUCTION}

The power generating system utilizing the natural energy such as wind power and solar power attracts attention recently from the standpoint of the global environmental problems. It is necessary to develop technology for the stabilization of power for the purpose of the utilization of electrical power generated by the natural energy which fluctuates vastly. Most of the power generating systems at present utilizing wind power and solar energy realize the stable power supply combined with a commercial power system.

Because totally-dependent natural energy power generation systems can not be applied on isolated islands or desolate areas, the new technology development of stable power supply by natural energy is necessary. Because of this, stand-alone type wind power and solar power generation hybrid system is developed in parallel combination with batteries and EG.

This paper explains the concept of the whole system and the active and reactive power control and the dump power control as the main control techniques, and describes the effectiveness of the system. In Section II, the system configuration is proposed. In Section III and IV, the general system control method and the proposed dump power control method is described, respectively.

\section{SYSTEM CONCEPT}

\section{A. System configuration}

This stand-alone type hybrid system consists of a wind power inverter, a solar power inverter, a bidirectional inverter for battery generation (bidirectional inverter denoted hereafter), EG, and an operation control device to control these inverters. These inverters are connected in parallel, which realizes the redundant operation.

The basic operation on the system is to give the direction of "Operate or Stop" to the operation control device. This operation control device is an automatic operation system to control all the inverters, but the operating condition of each inverter can be set manually as an added feature. Fig. 1 shows the system configuration.

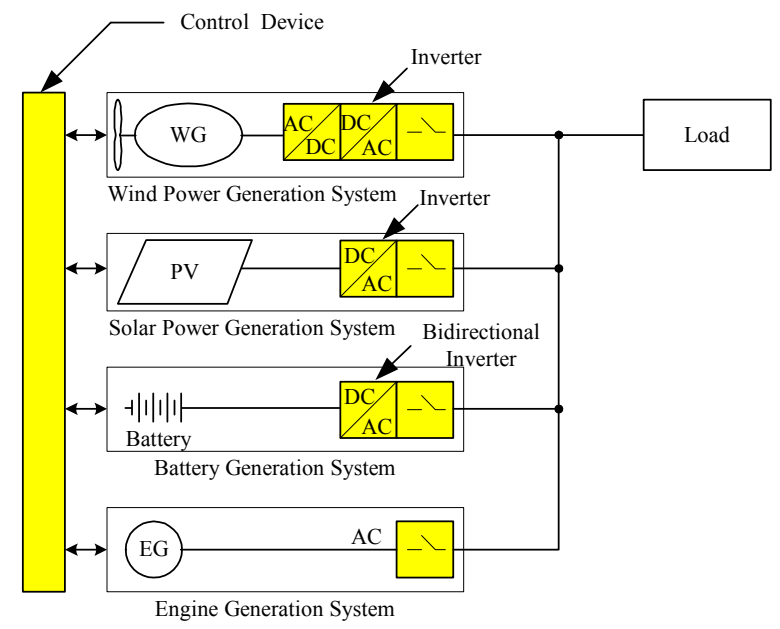

Fig. 1. System Configuration.

\section{B. System Operation}

In Fig. 2 is shown the concept of the system operation. The operation is classified into 2 categories: sufficient remaining capacity of the battery and insufficient remaining capacity of the battery.

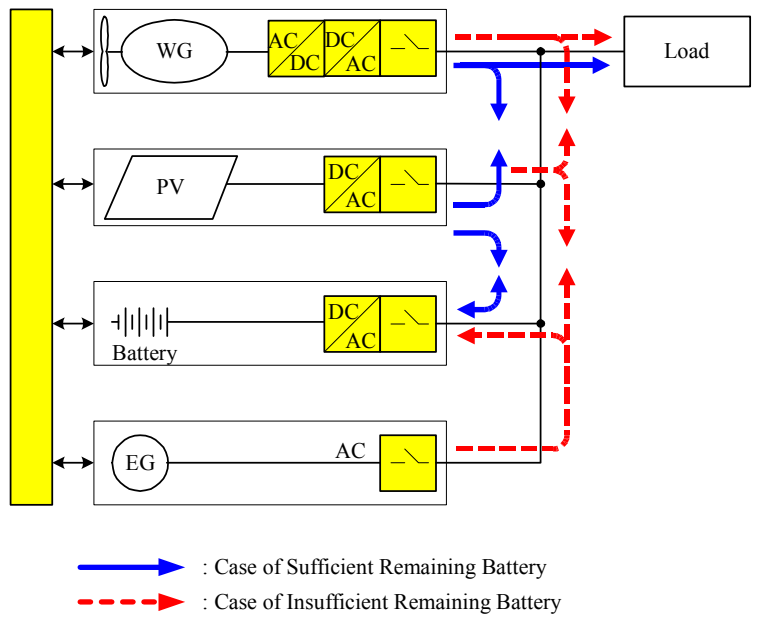

Fig. 2. Concept of System Operation. 
1) Case of Sufficient Remaining Battery

EG stops. A wind power inverter, a solar power inverter and a bidirectional inverter are in parallel operation. Excess and deficiency power produced between natural energy and the demand of loads is supplemented by the charging and discharging of storage battery.

2) Case of Insufficient Remaining Battery

EG is operated. A wind power inverter, a solar power inverter, a bi-directional inverter and EG are operated in a parallel. EG supplies electrical power to a load and charges battery through the bidirectional inverter at the same time. The bidirectional inverter controls the charging power to the battery so as to put EG in the most optimum power generating conditions according to the direction by the operation control device.

\section{SYSTEM CONTROL}

In Fig. 3 is shown the basic control block diagram of power control. When EG is operating, A contacts of all the inverters are closed, and are all the inverters in AC-synchronized operation under the slave mode with EG as a master.

When EG is stopped, B contacts of the bidirectional inverter is closed, and the bidirectional inverter is in CVCF operation as a master. All the other inverters are contracted to $\mathrm{A}$ and are in AC-synchronized mode under slave mode.

In Fig. 4 is shown the parallel operation model of the inverters. Under the condition that the capacity of each inverter is $3 \mathrm{kVA}$ (with power factor as 0.8 ) and the output voltage is $100 \mathrm{~V} 60 \mathrm{~Hz}$, an investigation of each parameter is carried out to control the system and generate this power. Here it assumed that the active power is $P_{s m}$ and the reactive power is $Q_{s m}$ on the sending end, that the active power is $P_{r m}$ and the reactive power is $Q_{r m}$ on the receiving end, and that the reactance of the reactor in the interconnection tie is $X_{m}$, where $\mathrm{m}$ is paralleled system number.

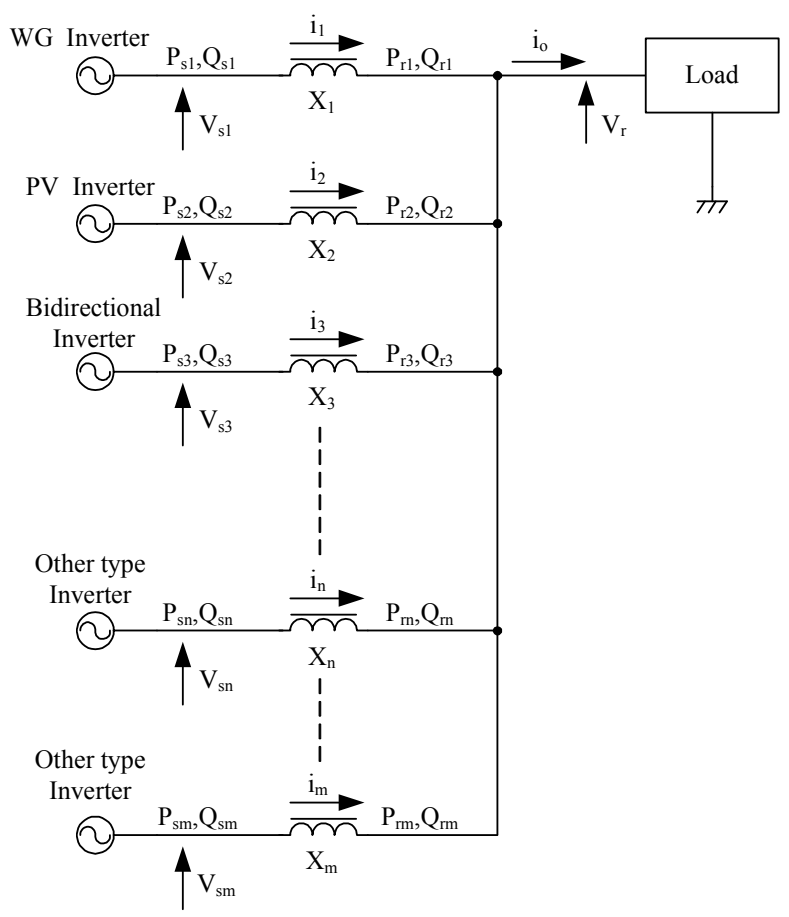

Fig. 4. Parallel Operation Model of Inverter.

Assuming that $V_{s m}$ is the sending end voltage, $V_{r}$ the receiving end voltage, and the angle of the phase difference, $P_{s m}$, $Q_{s m}, P_{r m}$, and $Q_{r m}$ are represented as follows

$$
\begin{gathered}
P_{s m}=P_{r m}=\frac{V_{s m} V_{r}}{X_{m}} \operatorname{SIN} \delta \\
Q_{s m}=\frac{V_{s m}{ }^{2}-V_{s m} V_{r} \operatorname{COS} \delta}{X_{m}}
\end{gathered}
$$

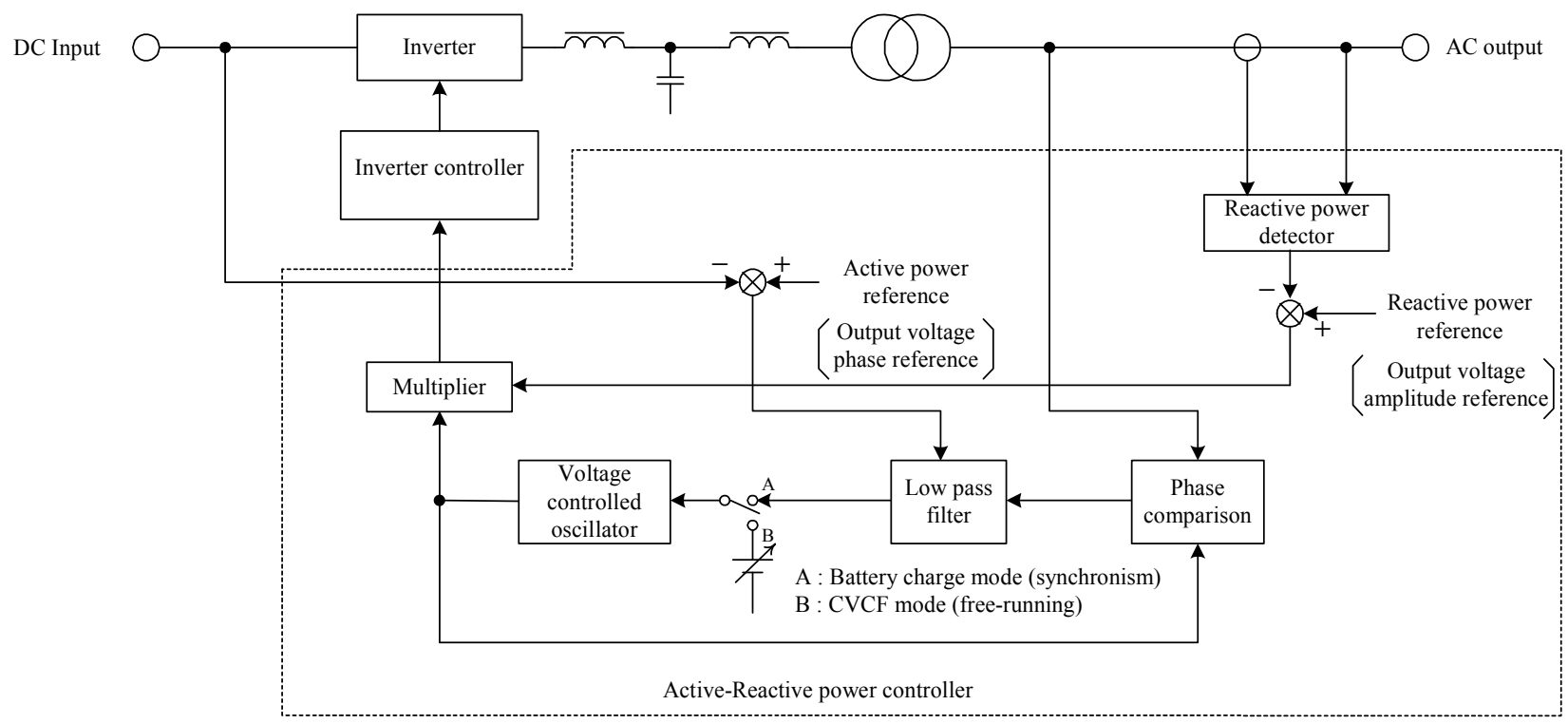

Fig. 3. Basic Block Diagram of Power Control. 


$$
Q_{r m}=\frac{V_{s m} V_{r} \operatorname{COS} \delta-V_{r}^{2}}{X_{m}}
$$

It is desirable to control the voltage amplitude difference and the angle of phase difference to be 5 to $15 \mathrm{~V}$ and 5 to $10^{\circ}$, respectively, judging from the characteristics of the active and reactive power control operations as shown in Fig.3. When the

is $7.5^{\circ}$ and $V_{r}$ is $100 \mathrm{~V}, V_{s m}$ becomes $109 \mathrm{~V}$ by use of Eq's (1) and (2). The reactor in the interconnection tie becomes $1.57 \mathrm{mH}$.

In Fig.5 are shown the current and voltage waveforms of each inverter of engineering model. This diagram shows that the active power is supplied to the load by the wind power and solar power inverters $50 \%$ each under the condition that the reactive power of the bidirectional inverter becomes zero. The load capacity is $3 \mathrm{kVA}$ and the power factor is 0.8 .

The test results are considered in the following.

As for the bidirectional inverter, the output voltage agrees on both the phase and the amplitude compared with the voltage of the load. The output current hardly flows. As for the wind power and solar power inverters, the voltage phase is $4^{\circ}$ in advance and the voltage amplitude is 8 to 9 volts higher compared with the load voltage. 15A of the output current flows from each inverter.

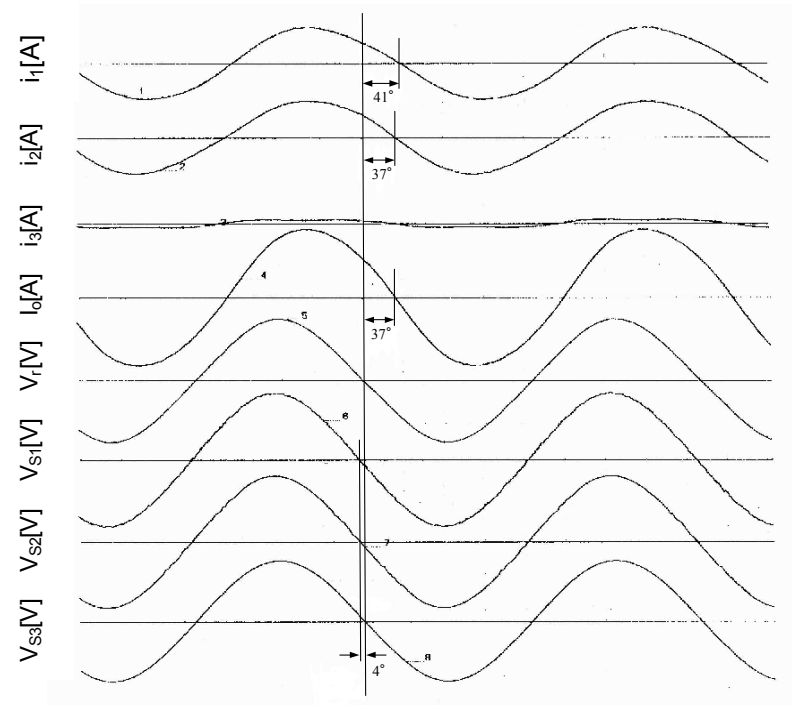

Fig. 5. Current and Voltage Waveforms of Inverters.
This tells that the wind power inverter and the solar power inverter supply $12 \mathrm{~A}$ of the active current and $9 \mathrm{~A}$ of the reactive current to the load respectively. The test results are shown in Table 1.( ) is theoretical value.

The theoretical values quite agree on the experimental ones when it is considered that the loss of the output transformers and their leakage inductances are neglected.

It is confirmed that each inverter controls the output power in optimum conditions by this reactive power control (amplitude control) and the active power control (phase control).

Also, Figs. 6 and 7 show charging voltage vs. charging current and the waveforms of which the bidirectional inverter is operated in the slave mode. From the figures, it is shown that the charging is realized with the constant current and voltage.

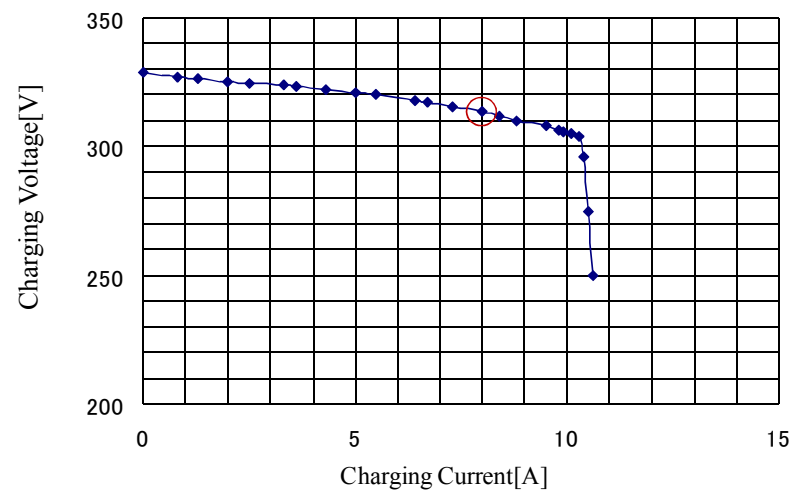

Fig. 6. Charging current and voltage characteristics of the battery.

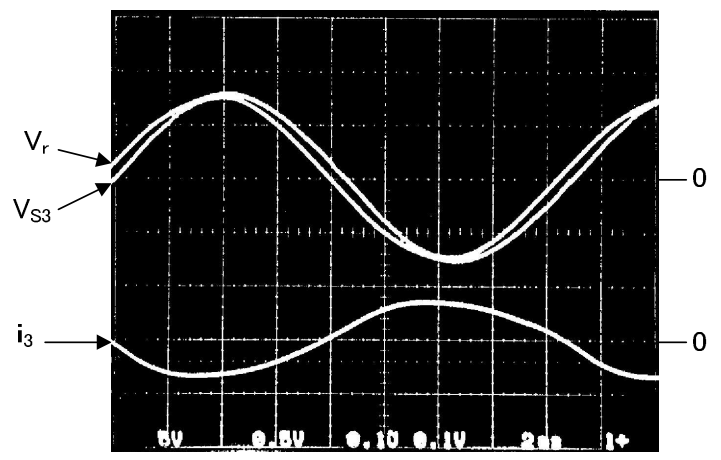

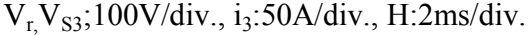

Fig. 7. Waveforms of the bidirectional inverter at the charging current 8A.(Red circled in Fig. 6).

TABLE I TEST RESULTS

\begin{tabular}{|c|c|c|c|c|c|c|}
\hline & \multicolumn{2}{|c|}{ Voltage } & \multicolumn{2}{|c|}{ Apparent current } & \multirow{2}{*}{$\begin{array}{l}\text { Active } \\
\text { current }\end{array}$} & \multirow{2}{*}{$\begin{array}{l}\text { Reactive } \\
\text { current }\end{array}$} \\
\hline & Amplitude & Phase & Amplitude & Phase & & \\
\hline Bidirectional Inverter & $\begin{array}{c}100 \mathrm{~V} \\
(100 \mathrm{~V})\end{array}$ & $\begin{array}{c}0^{\circ} \\
\left(0^{\circ}\right)\end{array}$ & $\begin{array}{c}2 \mathrm{~A} \\
(0 \mathrm{~A})\end{array}$ & $\begin{array}{c}0^{\circ} \\
\left(0^{\circ}\right)\end{array}$ & $(0 \mathrm{~A})$ & $(0 \mathrm{~A})$ \\
\hline Wind Power Inverter & $\begin{array}{c}108 \mathrm{~V} \\
(105.6)\end{array}$ & $\begin{array}{c}4^{\circ} \\
\left(3.86^{\circ}\right)\end{array}$ & $\begin{array}{c}15 \mathrm{~A} \\
(15 \mathrm{~A})\end{array}$ & $\begin{array}{c}41^{\circ} \\
\left(36.9^{\circ}\right)\end{array}$ & $\begin{array}{c}12 \mathrm{~A} \\
(12 \mathrm{~A})\end{array}$ & $\begin{array}{c}9 \mathrm{~A} \\
(9 \mathrm{~A})\end{array}$ \\
\hline Solar Power Inverter & $\begin{array}{c}109 \mathrm{~V} \\
(105.6)\end{array}$ & $\begin{array}{c}4^{\circ} \\
\left(3.86^{\circ}\right)\end{array}$ & $\begin{array}{c}15 \mathrm{~A} \\
(15 \mathrm{~A})\end{array}$ & $\begin{array}{c}37^{\circ} \\
\left(36.9^{\circ}\right)\end{array}$ & $\begin{array}{c}12 \mathrm{~A} \\
(12 \mathrm{~A})\end{array}$ & $\begin{array}{c}9 \mathrm{~A} \\
(9 \mathrm{~A})\end{array}$ \\
\hline Load & $\begin{array}{c}100 \mathrm{~V} \\
(100 \mathrm{~V})\end{array}$ & $\begin{array}{c}0^{\circ} \\
\left(0^{\circ}\right)\end{array}$ & $\begin{array}{c}30 \mathrm{~A} \\
(30 \mathrm{~A})\end{array}$ & $\begin{array}{c}37^{\circ} \\
\left(36.9^{\circ}\right)\end{array}$ & $\begin{array}{c}24 \mathrm{~A} \\
(24 \mathrm{~A})\end{array}$ & $\begin{array}{c}18 \mathrm{~A} \\
(18 \mathrm{~A})\end{array}$ \\
\hline
\end{tabular}




\section{DUMP POWER CONTROL}

In case of EG stops and the bidirectional inverter is CVCF operated in master mode, the dump power, which is, the generated power minus the demand of loads, is utilized as the charging power for the battery, when either the wind power generation or the solar power generation becomes greater than the demand of loads.

At this time the optimum charging is made and the overcharging has to be prevented.

In Fig. 8 are shown the conventional method of dump power control.

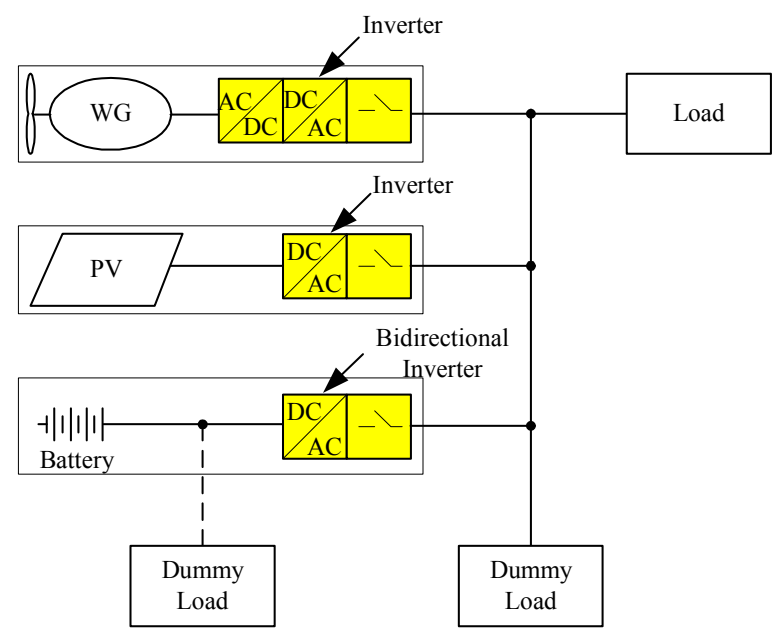

Fig. 8.The conventional method of dump power control.

According to the conventional method, the dummy load (resistor load or radiator) is installed in parallel with the battery or the AC-supplied terminal. But the dump power is not always constant, and fluctuating. It is difficult to control the dummy load which consumes excess power.

That is, the dummy load is ON or OFF. Therefore, it is very difficult to control the load in details analog-wise. The problem of the control method is that the optimum charging current and voltage cannot be kept to the battery.

The new control method of the dump power devised this time does not need any dummy load to control the dump pow-

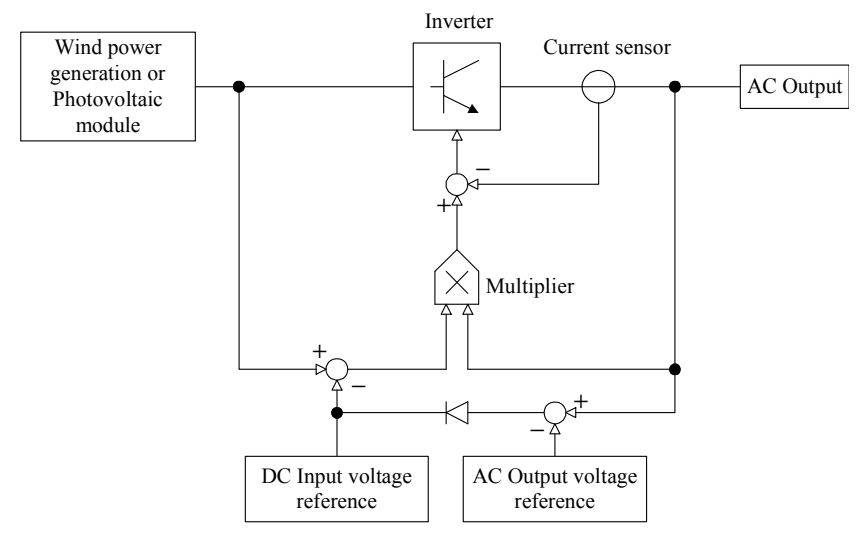

Fig. 9. Dump Power Control Block Diagram of Wind and Solar Power Inverter.

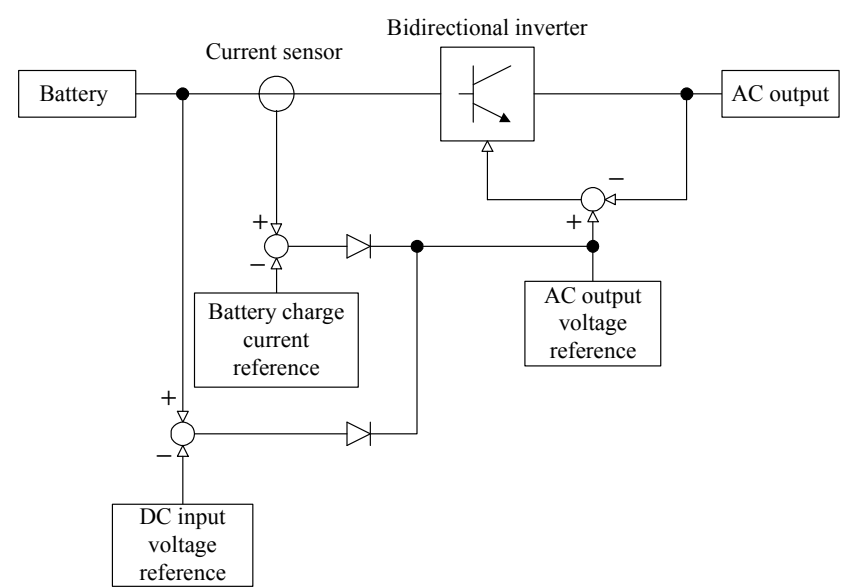

Fig. 10. Dump Power Control Block Diagram of Bidirectional Inverter.

er. Furthermore, because it is controlled analog-wise, the device makes a quick response to the fluctuating dump power and does not control the dump power more frequently than required. Therefore, this will realize the optimum utilization of natural energy.

In Fig. 9 is shown the block diagram of controlling the dump power from the wind power or solar power inverter. In Fig. 10 is shown the block diagram of controlling the dump power from the bidirectional inverter.

In the following is described the control method of the dump power.

When the dump power occurs, this power flows into the battery through the bidirectional inverter. At this time the current flowing into the battery is sensed by the current sensor. If the current exceeds the value of the charging current reference, the difference is amplified and added to the value of the $\mathrm{AC}$ voltage reference. If the voltage of the battery exceeds the value of the charging voltage reference, the difference is amplified and added to the value of the AC voltage reference. That is to say, the voltage of the AC reference increases, and therefore, the output voltage of the bidirectional inverter increases.

When the voltage of the bidirectional inverter increases, the output voltage of the wind power generator or the solar power generator is increased by the reactive power control. Therefore, if this output voltage becomes greater than the value of the AC output voltage reference, the difference is amplified and added to the value of the DC voltage reference.

Because the output voltage of the wind power generator or the solar power generator is controlled by the value of the DC voltage reference, the output voltage decreases as the value of the $\mathrm{DC}$ voltage reference increases.

Therefore, as the whole feedback system is formed and the dump power is controlled. The charging current and the charging voltage are kept constant to the battery.

The features of the dump power control mechanism developed this time are described as follows.

1) A dummy load and its control are not needed. 
2) Because the control is made analog-wise, it is possible to control the dump power in details. Thus, the over-charging the battery is prevented and the life of the battery is extended.

3) Because the information exchange is made through the power lines, the signal lines between the systems are not necessary. Therefore, the distributed arrangements of the systems become easy. At the same time the future expansion of the systems become easy.

\section{CONCLUSION}

The stand-alone type hybrid power generating system was constructed. The control methods of the active and reactive power, and of the dump power were developed this time.

As the features of the hybrid system developed, the following can be mentioned.

1) Each system or EG can be connected on the power line anywhere and the stabilization of the $\mathrm{AC}$ voltage is possible due to the reactive control of the inverters.

2) The widely distributed system is possible because the distribution lines are shared to the power lines.

The global environmental problems and the modernization of the isolated areas are contradictory ones. It is expected that this hybrid power generating system utilizing natural energy will be compatible with these problems.

\section{ACKNOWLEDGMENT}

As for this research, a deep gratitude is given to Mr. Kohji Takase with Nishimu Electronics Industries Co., Ltd.

\section{REFERENCES}

[1] N.Kato, K.Kurozumi, N.Suzuki and S.Muroyama;"HYBRID POWERSUPPLY SYSTEM COMPOSED OF PHOTOVOLTAIC AND FUELCELL SYSTEM,"Proceedings of INTELEC 2001(CDROM), 096.pdf, 2001. 